\title{
INSTITUTION BUILDING FOR IT GOVERNANCE AND MANAGEMENT
}

\author{
Velizar SHALAMANOV
}

\begin{abstract}
Institution building and change management for IT organizations is challenging even for small cases. Success rates can be improved by careful collection of verified good practices. NATO experience provides examples of good practice. Learning from one of the largest efforts in NATO Reform, launched after the 2010 Lisbon Summit, i.e. the establishment of the NATO Communications and Information Agency (NCIA) is indispensable. The focus of this article is on the identification of the process and related good practices and, in some cases, recognizing mistakes to be escaped in the future. It presents an attempt to structure the experience as a methodology to support institution building and change management in similar service-based or technology-oriented organizations. The transition from five different organizations to one service-based and customer-funded agency is reviewed in the framework of the NATO Comprehensive C4ISR Approach, noted by Nations in November 2009, considered as an appropriate framework to present and understand the process of change.
\end{abstract}

Keywords: IT management, IT governance, good practices, institution building, change management, NATO, NCIA.

\section{Introduction}

This paper is based on the practical experience of the author in the period 2009-2016 when he was director sponsor account NATO \& Nations in the NATO Consultation, Command and Control Agency (NC3A, 2009-2012) and director demand management in the successor - the NATO Communications and Information Agency (NCIA, 2013-2017), and participated in all stages of transforming five ICT agencies in one C\&I Agency for the whole NATO and Nations, both members and partners.

This change was in the context of overall NATO reform. At the Lisbon Summit, in November 2010, NATO leaders endorsed a new Strategic Concept, which states that the Alliance will "engage in a process of continual reform, to streamline structures, improve working methods and maximize efficiency." This reform continued through a long term adaptation initiative, especially its institutional dimension in addition to political and military aspects.

Building service based and customer funded (focused) C\&I agency by merging five different bodies to achieve effectiveness, efficiency and 20\% savings for NATO C\&I 
organization stakeholders in 3-5 years (practically, seven years with two years of preparation), when maintaining quality of service to all existing and many new customers in the security environment that dramatically changed after 2014 (Russian aggression to Ukraine - annexation of Crimea and support to rebels in Eastern Ukraine, rise of ISIS and overall instability in MENA region) was all but a trivial task.

Conceptual framework for the review and analysis of the transition is noted by the Nations in the 2009 NATO Comprehensive C4ISR Approach with three pillars: ${ }^{1}$ (1) extended customer base, including not just NATO common funded structures and national defence organizations, but the whole security sector, and not only of NATO members, but of partner countries as well (including various multinational organizations); (2) integrated approach to the life cycle of C4ISR capabilities - from R\&D through procurement to operation and maintenance (service provision), retirement and utilization; and (3) combining all available and developing new innovative funding mechanisms in addition to common funding - national and multinational funding, trust funds, mechanisms for work sharing with academic/ non-for-profit organizations.

This topic is very important nowadays, because IT is developing fast and as a result management of its implementation in business organizations is facing the challenge of growing cost, difficult integration and cyber risks. Recently, and not only under NATO Agency Reform, massive change management effort is going on in the IT area. Most of NATO nations are reorganizing their IT support and cyber defence organizations seeking effectiveness, efficiency and better resilience with a control over expenditures (cost).

The paper presents the framework for IT governance and management, describes key areas as seen by the author, where change is taking place and lessons are drafted. Based on that, it outlines a way ahead and provides conclusions on using NCIA generated experience.

\section{General Framework and Maturity Levels for IT Governance/ Manage- ment (ITG/M)}

Conceptual framework is important from the governance and management prospective, because the Agencies' reform task creates a complex operating environment and requires high level of maturity of the organization in order to be effective, efficient and able to reach mandated savings.

The general framework for governance and management of enterprise IT is COBIT 5 , based on five key principles: ${ }^{2}$

Principle 1: Meeting Stakeholder Needs;

Principle 2: Covering the Enterprise End-to-End;

Principle 3: Applying a Single, Integrated Framework;

Principle 4: Enabling a Holistic Approach; 
Principle 5: Separating Governance from Management.

There are five levels used in this transition, defined along the continuum of the maturity model: ${ }^{3}$

1. Initial (chaotic, ad hoc, individual heroics) - the starting point for use of a new or undocumented repeat process (strong reliance on people and common sense, previous experience);

2. Repeatable - the process is at least documented sufficiently so that repeating the same steps may be attempted (there are at least simple Terms of Reference $/ \mathrm{ToR} /$ for the processes and written statement of work for key positions);

3. Defined - the process is defined/confirmed as a standard business process (Standing Operating Procedures / SOP/ are available along with coordinated job descriptions);

4. Capable - the process is quantitatively managed in accordance with agreedupon metrics (dashboards at management and governance level are established);

5. Efficient - process management includes deliberate process optimization/ improvement (processes, organization, technology and people are fully integrated with a mechanism for continuous improvement/ adaptation).

The goal was to move to level of maturity 3-4, understanding that initial consolidation was leading to an organization of level 1-2 of maturity as a whole.

The paper is covering key issues of this transformation with lessons learnt that could be useful in building similar complex IT organizations on National or Multinational level.

It is important to stress that all these different aspects of institution building and change management are interrelated and need synchronization under the strategic vision, through unity of leadership and required fluidity of resources to implement the "Fast Strategy" model. ${ }^{4}$

Achieving greatness will require "fanatic discipline," "productive paranoia," "empirical creativity," and "level 5 ambition."

This paper is to provide a baseline for success in building IT governance and management in complex organizations, based on critical analysis and drafted lessons learnt from the specific case of setting up NCIA for the period 2010-2017. Normally, change in IT organization goes hand in hand with the changes of the business organization served. This was exactly the case in NCIA, formed as part of the Agency reform, which on its own was part of NATO reform that started after the Lisbon Summit in 2010. Further development of NCIA is part of institutional adaptation - one of the three dimensions of the Long term NATO adaptation after 2014.

Short review of key aspects of development of IT organizations with focus on governance and management is to identify lessons to be used in the institution building process for similar National or multinational IT organizations, especially if they 
are to collaborate with NCIA in the partnership network of NATO Nations and partners with similar C\&I structures.

Focus is really on building and change management of IT organization, but in general covered aspects are applicable to any type of service based technology organization.

The paper tries to provide comprehensive review of different aspects, recognizing that each of these aspects will require deeper analysis and study of key problems with respective solutions.

For this paper the key aspects covered are: business case and mandate; establishment of governance and management structure; organization of strategic and business planning; organizational development and change management/ continuous improvement of the IT organization; organizational culture and strategic communication; partnership with the customers and account management; IT architecture and Service Catalogue; Portfolio, program, project management (capability development); service management and control; engine room of the IT organization; cyber resilience; project and service level agreements; risk management; personnel management; innovation and technology management; financial management (customer funding); acquisition and outsourcing; legal support; facility management and general support; role of consultants; internal and external audit and correction planning.

The long list above is required by the comprehensive approach to governance / management of IT/ICT for security, but of course real life challenge us with other aspects and problems in implementation of the institution building and change management model, identified by the study of NCIA case (2010-2017).

The paper is a foundation for the structured consultation in planning institutional development and change management of IT organizations. In every specific case, in addition to the key lessons identified here, a lot of additional considerations have to be taken in account to define the best solution for the IT organization concerned. As mentioned the approach is applicable in great sense to any type of service based organization or technology based organization as well. For example it is possible to use this approach for supporting institution building and change management of Public administration (PA) as service provider to the citizens/business as well as to the IT organization supporting e-Government based PA.

\section{Key Areas of Institution Building and Change Management}

In this chapter we will review areas of institution building and change management, identified by the author based on the experience in NC3A/NCIA, but valid for any type of IT organization, supporting large public customer base.

\section{Mandate for the IT Organization}

IT support could be mandated to internal organization as a whole or outsourced to external one to the business organization. In any case mandate is to provide clarity 
for the scope of support required and business model of providing such a support, to set up business goals for the IT support.

Normally agreement on a specific mandate between stakeholders is based on a business case with various options and their SWOT (Strengths, Weaknesses, Opportunities and Threats) analysis. Development of business case requires PEST (Political, Economic, Social, Technological) analysis to identify possible options.

Key lesson is to engage all the stakeholders in consultations for defining the mandate with its approval on highest possible level of the business organization, supported by the IT structure mandated. Mandate is not just authority, but key mission and its parameters, including resource component. Lack of a business case and clear mandate is limiting the understanding and support to the complex task of building IT organization and could undermine the effort with potentially high cost as well.

\section{Governance and Management for IT}

In any case we need distinction between Governance (strategic guidance, decision making on business goals / tasks and resources for IT Organization) and Management (effective and efficient implementation of business goals/ tasks in the frame of provided resources and rules), as well as daily operation of the IT organization.

For the governance function we need IT Organization Supervisory Board, representing key stakeholders (funding organizations). For the management we need professional leadership team of the implementation body for the IT Organization.

Key factor for success is engagement and close cooperation with all the stakeholders of the IT organization by the leadership team. Key lesson is to apply proper way COBIT Principle 5: Separating Governance from Management in order to create space for operation in stable enough environment.

\section{Strategic and Business Planning}

Strategic planning is to include the strategic guidance from the governance body and its implementation through strategic plan (prepared by the management leadership team in consultation and for approval of the governance body). The business plan of the implementation body of the IT organization is a next step to clarify three year operation with the focus on the first (next) year.

Strategic Plan is to reflect mandate and guidance, defining key change/ improvement goals in long to mid-term. It is referring to Mission and Vision for the agency (based on the mandate) and is setting goals in different areas (customer, finance, processes, learning and development ${ }^{6}$ ) with respective strategic initiatives. Thus, it is a plan directed both outside and inside the agency (implementation body of the IT organization). This plan is sole responsibility of the General Manager/ CEO (Chief Executive Officer) of the implementation organization, even based on intensive consultations inside and outside the IT organization.

The Business Plan defines implementation of the business goals with the available resources in short term to annual timeframe and in a customer funded organization it 
is based on demand assessment and projected revenue. This plan is sole responsibility of the Chief Operating Officer (COO), who is a key business manager inside the organization and the plan is inward looking, but shared with key customers; performance is measured periodically against this plan with proper information going to the customers. The Business Plan is approved by the governance body.

The Strategic plan itself could introduce changes in the business model, when the business plan is based on current business model and agreed key assumptions for 1-3 years.

All other planning documents are either annexes to the strategic plan or to the business plan, except the Financial plan, that under the arrangement of the customer funding goes up to the resource governing bodies in the business organization, the IT organization is serving/ supporting. Financial Plan is a sole responsibility of the Chief Financial Officer (CFO).

This arrangement creates a triangle of $\mathrm{CEO}, \mathrm{COO}$ and $\mathrm{CFO}$, but having in mind that the IT organization we are looking at is customer funded and service based, we need to mention another two Chief Officers - Chief Customer Officer (CCO) to develop demand assessment and Chief Technology Officer (CTO) to maintain the Catalogue of services and key competencies for the projects. So the central team for planning is extended to five Chief Officers - CEO, COO, CFO, CCO and CTO. Of course, all of them work with the leaders in production segment as well as key enablers as HR management, General support services in order to balance demand and supply on strategic and operational level.

Key lesson in this area is that the IT organization needs stable planning and reporting process with all the key Chief Officers involved in accordance of the RACI (Responsible, Accountable, Consulted, Informed) Matrix of the process. This planning process is the key requirement to move even to the second level of maturity and definitely is a core prerequisite for the third level of maturity.

\section{Organizational Development and Change Management; Continuous Improve- ment}

IT organizations, depending on mandate and strategic guidance, will need organizational development plan to drive the change management as part of the Strategic plan. Organizational development itself is based on process design and definition of the RACI (responsible, accountable, consulted, informed) matrix for the key leaders of the key processes as defined by the general manager/CEO, according to his or her vision to implement the mandate.

Form, Storm, Norm, Perform stages (see the diagram below) include change management in first three steps and continuous improvement for the last one, until new mandate is provided for the IT Organization to initiate a new change management program. 


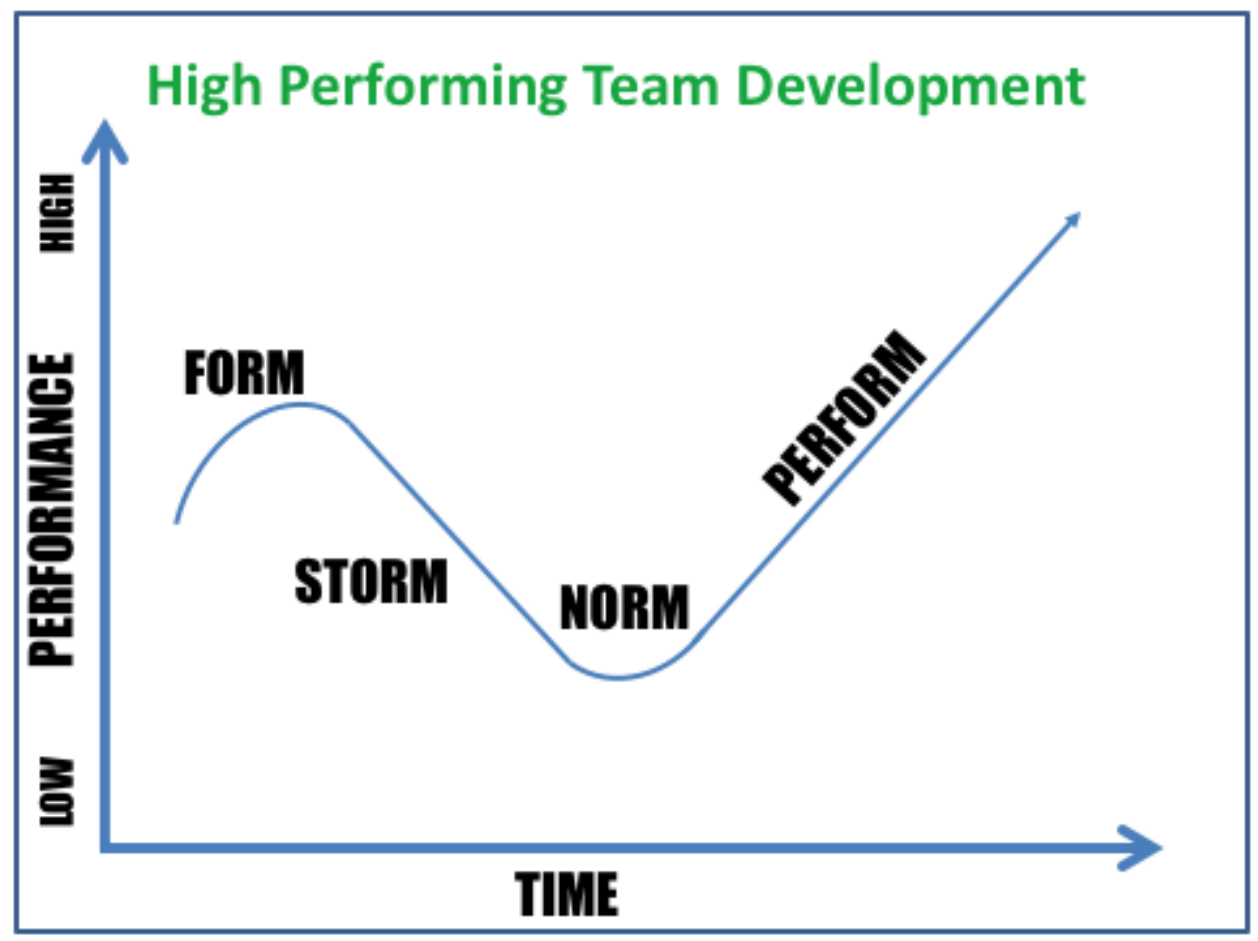

Figure 1: Model for team development, used also for organizational development.

As the change is a key strategic issue, the leading role is for the CEO, supported by the leadership team and set of agents of change. Key for the change is the re-engineering of the processes, but organizational design as well, introducing technologies and, most of all, training/ retraining of the personnel, strategic communication (internal and external) - all these resourced and synchronized.

There are different frameworks for Strategic planning and change management, but what Balance Score Cards and Strategic Maps ${ }^{7}$ provide is good enough and tested in NC3A/NCIA strategic planning with ADKAR methodology ${ }^{8}$ for the change management aspect.

Key lesson in this area is to provide strong leadership from CEO level and identify proper support framework for change management (including Organizational development) in order to have manageable process with clear indicators, measurement mechanism for reporting and assessment by the governance body, periodic audit missions and corrective plans, based on best practices and maturity levels description.

A good practice to mention here is the establishment of "red team" to review proposals for change from transition teams, before going with these proposals to the executive board for decision. 


\section{Organizational Culture and Strategic Communication}

Change management effort is complete when a new culture is established in the IT organization and its stakeholders/ customers. Strategic communication-external and internal-is the critical factor to develop and strengthen the new culture.

This aspect is considered separately from overall change management, due to its importance and overarching nature. In the same way as we need to measure customer satisfaction in order to drive the change towards external world, we need proper measurement of the organizational culture development and maturity in order to drive internal change. Both internal and external strategic communication is focused on strengthening the positive achievements and shaping change in the areas where we still experience problems.

Key lesson is to have this effort as a separate strategic initiative and at the same time to integrate with other key initiatives as an instrument for maintaining feedback and actively shaping the environment.

\section{Partnership with the Customers and Account Management}

From the point of view of value delivery process, the first step is engaging customers to build understanding of the demand and develop partnership.

For effective support of the customers the segmentation is required and development of strong account management teams for different segments is mandatory.

Building effective partnership requires good measurement of customer satisfaction and using it to inform all the changes to achieve higher level of support from the customers, to seek real partnership relations and work as one team for common success.

Chief Customer Officer is part of the Chief Officers team, working both to COO for demand assessment, but directly with CEO for partnership development.

Based on horizontal segmentation we could consider vertical segmentation as well to define key accounts for the limited number of senior customers (large portfolio, critical importance for the success of the overall organization supported) and for the rest - large diverse base of customers in separate accounts. Based on priorities we could move some accounts from general group of accounts to senior group of accounts.

In NATO case there is a division between common funded (internal) customers and nationally/ multinationally funded (external) customers that in general covers division between senior customers - all internal ones and general customers-all external ones.

Segmentation - horizontal and vertical — of the customers in different accounts provide opportunity for tailored approach in engagement and customer satisfaction assessment.

Key lesson is to provide proper level of transparency to the customers through different initiatives/ instruments (Senior Customer-Supplier/ Partnership Board, CIO Con- 
ference, planning meetings, partnership agreements, CRM /customer relationship management/ surveys, etc.) for building trust and development of joint solutions to the problems faced in the area of capability development and mostly service provision. For the success of the partnership is critical to understand the core business of the supported organization.

\section{IT Architecture and Service Catalogue}

The basis for effective engagement and development of proposals is the Service Catalogue of the IT organization, dependent of the IT architecture to support different services.

Effective IT organization is a service-based one, not asset management focused. It means that all the assets are transformed in capabilities and they are transitioned to services with key performance indicators (KPI) and cost. The services are presented in the catalogue with the business model to consume these services, if required (to be used in the development of service level agreements, or SLA).

Without having good understanding of the architecture, dependence on external outsourced services, internal dependencies between assets and provided services to the customer, it is not possible to develop KPIs and to start collecting data for calculating the real cost of the service, assess the risk and plan mitigation.

At the same time, the Catalogue is not a fixed document - services will change every year if not more often as a result of technology change or requirements evolution. Customer catalogue present current services, but always there are pipeline services and retired services to be managed by the IT organization and mapped with the supporting architecture.

Key lesson is that transition to service based organization will require good understanding of the IT architecture and its effective internal management, together with the business model of delivering services by the IT assets/ capability.

\section{Portfolio, Program, Project Management - Capability Development}

IT infrastructure and applications along agreed architecture are built through large portfolio of programs and projects managed by using PRINCE II (project management in controlled environment) for project management and MSP (managing successful programs) for program management. ${ }^{9}$

IT organization could finance projects / programs using portion of the fee for service based SLAs (Service Level Agreements), agreed with the customers to support technology refresh or improving of the services, even adding new services. In other governance arrangements, the investments for the new services or improvement of existing ones could come from dedicated funding under different mechanism of decision making (separate from service fees).

Key lesson is that in service based organization all projects and programs have to be designed to cover the transition to service, and retired services will require project support until they are "fully deleted" from the system. 


\section{Service Management and Control}

In principle, being service based organization the centre of the development is the service provision and ITIL (Information Technology Infrastructure Library) V3 is used as a set of good practices for improving the maturity of the organization. ${ }^{10}$ This is why a Network Control Centre (NOC) with cells for applications management and related CERT/CIRC (computer emergency response team/ computer incidents response capability/centre) are key operational elements for $24 / 7$ in service provision environment (connectivity, functionality, resilience).

Proper control of KPI and providing mitigation measures / compensations when SLA agreed parameters cannot be met is part of the provision model. In the specific cases of reducing some levels of service, based on priority of customers and their requirements an additional set of mitigation and compensation measures is needed, with early warning to the extent possible.

Lesson to learn in the area is that reporting and partnership with customers are very important in a transition period to service based organization, when at the same time the governance body has to provide support from the resource community to address the requirements for the customer funded services.

\section{Engine Room}

Core of the organization at the end of the day is in the service lines, managing capability development, their transition to service and the management of these services centrally and locally at the delivery points.

This is where the change and continuity meet with high risk for the success of the organization as a whole - on one side we need stability in production line to deliver active services and at the same time managing the process of developing new capabilities for improved or new services, transition of these capabilities to service and retiring services already replaced or obsolete.

There are at least two potential conflicts in the matrix of service lines/ point of delivery units on one side and between customer engagement/ agreement (account) management teams and point of delivery units. Managing these relations between the Customer engagement, Production, Delivery (service operations) leaders/ teams is more an art than science. If one adds to this key point of friction the role of Chief Architect (part of CTO team) dealing with coherency, and Chief Financial Officer, focusing on financial performance - we receive a good idea of what is the challenge of the Chief Operating Officer, dedicated to the task to make all this working smoothly on a daily basis.

On one side, biggest savings could come from the engine - being the largest element of the IT organization, while on the other side for engine to operate, we need stability and continuity. Good delineation between Management team of Chief Officers and the Engine (production) is a prerequisite for effective IT organization and we need to learn well this lesson. 
The engine itself to operate properly will require a lot of OLAs (Operation Level Agreements) in order to build complex services with elements coming from several internal organizational structures.

\section{The Ultimate Challenge of Cyber Resilience}

With the ambition to provide more and more IT services of critical importance for the customer and through the infrastructure that is not owned/ controlled by the customer, it can be accepted that the ultimate service is Cyber resilience for all the IT services offered. That means we could consider cyber defence as part of any service in the catalogue and we do not compromise on this service.

Such a situation could put additional cost to the services for all the customers, but importance of the cyber security is high for the organization as a whole. That means the cost of this "internal" service could be funded centrally and with high certainty in order to keep high standard.

At the same time, if some of the services will require "federation" of customer infrastructure with the IT organization main infrastructure, we need very solid set of rules for accreditation of federated elements in order not to compromise cyber security of the core IT organization itself.

Key lesson is that cyber security cannot be added as a separate service at the end. Its integration in all other IT services is required, and one needs to consider cyber resilience from the very beginning of service design.

\section{Project and Service Level Agreements}

Being customer funded organization, the way to provide funding (outside dedicated transition program - even this program is a subject of approval of the governance body of higher rank as a customer for implementation of the mandate for change) is through agreements with the customers (either project agreement for building capability/ providing consultancy or service level agreement based on the costed service catalogue).

Putting together the agreement has to be simple enough in order to reduce the cost and focus on delivering results/ services - not on lengthy discussions / negotiations for sometimes small repeatable projects. As much as possible, these agreements are to be based on the Customer catalogue and standard business models of delivery of services or projects.

Even understanding that only signed and paid agreement is a foundation for project/ service delivery - it is a good practice to have multiyear planning with customers in order to assess the demand and plan capacity properly. Multi-year planning is very useful in support of multinational cooperation as well, because it provides opportunities to nations/ customers to adapt project opportunities to their priorities on one side and supports more flexible capacity planning on the IT organization side. 
Important lesson to learn is that agreements with IT organization being non-for-profit body and obliged to manage transparently funding from different sources/ customers, will require advance payment in order to start implementation.

\section{Risk Management}

As a complex organization, dealing with a lot of projects, programs and service delivery (including mission critical services) and in the same time managing change (especially in the storm - norm phases), the risk management arrangements are of high importance and responsibility of the leadership.

Defining the risk appetite and agreement with governance bodies and customers is a first step to establish a framework for risk management to include assessment of the probability and impact of every risk on the organization. In addition, the risk management is directly related to the cost of delivered projects and services.

Identifying internal and external factors, interdependencies between factors and risks and between risks themselves, identifying mitigation measures and responsibilities are all important elements of risk management.

Being central theme for the health of the organization, risk management even supported by professional team, remains responsibility of the senior leadership.

Key lesson is that risk management seminars at least twice a year at senior leadership level are mandatory to keep the organization aware of the risk probability and impact and to maintain clear responsibility for the mitigation measures according to the agreed risk appetite.

\section{Personnel Management}

The IT Organization is a typical knowledge/ technology based entity, where the personnel is the most critical factor for success. This issue is even more challenging nowadays as a result of high competition for skilled professionals on the labour market. In the case of public international organization, there are several additional limitations, related to rotation of the personnel on one side and limited flexibility for internal management of mobility.

Specific case for NATO and especially NCIA is the mixed model of civilian and military personnel under different authority and rules applicable. In this situation we still could use HR shared services centre, but definitely tailored personnel management is required for an IT organization.

One lesson to remember is that motivation of the people and availability of improvement programs, together with fair and open communication - especially on performance and retention - is key for overcoming the diverse risks in maintaining effective and efficient workforce. Even very attractive compensation packages cannot replace professional recruitment, talent management and professional development.

\section{Innovation and Technology Management}

IT organizations are challenged with rapid change of technologies. On one side, technology brings new services, reduce the cost of existing services, but the basic fact of 
rapid change brings complexity and vulnerability, especially in time of increasing sophistication of the cyber attacks.

All this places significant pressure on technology management and innovation. There are several embedded in each other cycles of change - technology, services, people, organization, even processes that require proper management from continuity and improvement of service point of view. Financial aspects of innovation and technology management are essential; funding these activities needs to be transparent and sufficient.

There is a special dimension when the IT organization is mandated with responsibilities for research and development (R\&D) and even science and technology (S\&T) activities. This will require development and management of specialized IT laboratories/ test-beds, that could be networked for research and experimentation internally and with other IT organizations. The latter is very often the case because research requires collaboration - from information sharing to joint experiments and testing.

Innovation cannot be driven only internally - very often it is based on participation in larger networks for science and technology as well as driven by the senior customers, who are leading in decisions for development of new capabilities and services from user perspective.

Key lesson to learn is that innovation cannot be expected as a side effect only, but requires special internal program, linked with larger network for science and technology collaboration.

\section{Financial Management (Customer Funding)}

In customer funding environment for the public (and international) organization, the financial management is not trivial. There are different streams of funding, under different rules (internal and external customers, capability development and service provision, NATO members and partners) and two modes - current operations and transition. The latter two influence each other and bring serious changes in customer rates and the very foundation of the cost definition for services and capabilities.

In such a situation, the very definition of the customer funding will require strong support from the governance bodies and senior customers. It is on one side important to have high degree of transparency, but on the other side, in order to manage the risk in the IT organization, we need certain flexibility in using funds in the framework of "break-even" for the period on no less than three years. This is a key challenge, since normally all the customers are budget funded organizations and they lack experience with customer funded public organization, tend to treat such an organization as an industry, which is not the case.

One good lesson is to put enough effort in defining the customer funding model, reach approval by the governance bodies and run effective education campaign internally and with the senior customers. Customer funding model for the services has to be able to support fee for service concept as soon as possible in transition. Model for costing in project agreements has to include risk management. 
Most critical aspect is the agreement with the governance bodies on management of the operating fund that is providing the flexibility in achieving "break-even" on a three-year cycle.

Important lesson to learn is on the role of relations among $\mathrm{CEO}, \mathrm{CFO}, \mathrm{COO}$, and $\mathrm{CCO}$ in financial risk management for "break-even," supported by the governing body. Very conservative CFO could block the IT organization, but very aggressive $\mathrm{COO}$ could increase the risk of a loss. Critical is the quality of enterprise business application (EBA) used in the organization to manage operating and planning data with focus on key customer funding indicators, used for financial/ resource management.

\section{Acquisition and Outsourcing}

It is normal for public organization to have limitations in the mandate of what to be performed internally and overall requirement to outsource to industry as much as possible in addition to normal acquisition of new capabilities.

Based on fluctuation of demand and required flexibility of the workforce, outsourcing by using contractors is a potential challenge in relation to customer rates based model for customer funding - normally contractors are more expensive than internal staff and increasing in year of the work to be covered by contractors obviously could bring a loss for the IT organization, using fixed price agreements.

Very specific case is related to outsourcing of $R \& D$ activities to public $R \& D$ organization in order to optimize the use of internal resources to what is the primary focus common funded acquisition of capabilities and service provision. With more external customers again the challenge is to outsource as much as possible and to keep in the IT organization only essential work, providing compliance to common standards, interoperability and security at large.

Experience brings lessons on effective management of contractors, use of basic ordering agreements, special arrangements of outsourcing $R \& D$ work to public research organizations and other mechanisms to provide for higher responsiveness and flexibility in service provision and to urgent requirements. On the other hand, for the large capability development programs additional challenges are to be met, that put diverse pressure on the acquisition team.

Good lesson is to have several mechanisms available and agreement how to use them in accordance with the acquisition problem to be addressed. But most of all, procurement rules have to be public and agreed by governance bodies, acceptable for the senior customers. Effective pre-procurement dialog with industry is required, so different forms of consultations need to be developed.

Fair distribution of information to industry about potential business is a good practice to follow and regular industry conferences to present the opportunities and changes in business model are required. 


\section{Legal Support}

The complex IT organization is characterised with many critical relations - with customers, industry, personnel, and other stakeholders. Certainly, most dynamic are arrangements with the customers, but in a transition period all the relations are changing and require review and proper legal arrangements.

Since these relations are maintained by different elements of the IT organizationcustomers under account management, industry under acquisition team, personnel with HR in lead, senior stakeholders relations managed by strategy group-it is important to involve the legal team in the early stages of the development of new type of relations to address the legal aspects. At the same time, accountable staff for these relations will need such legal instruments, that could be applied repeatedly in all standard cases without overloading the legal team with consulting in every regular case (of course exceptions will require legal involvement).

\section{Facilities Management and General Support}

Normally, IT organizations are quite integrated with the customer on the delivery side, but still operate some central facilities on their own and, due to the security dimension, need to have control over facilities of the contractor entities, involved in capability development or service provision. This scenario puts pressure on the general services team to manage complex set of OLAs (operation level agreements) internally and SLAs externally, in order to provide proper environment for the operation of the agency. Introducing "new way of working" as a mechanism to save expenditures for facilities, in addition to other benefits, is creating additional challenges to be addressed. One lesson is to define very well how the general support is optimized in order to keep the cost of IT support to the customer low because, after personnel, this is the second largest element of the cost of the services provided.

\section{Role of Consultants}

When it comes to organizational change, introducing new processes and technology, development of personnel and raising the maturity level, and change of culture - it is essential to use external consultants. There are at least three reasons for this: it brings specific knowledge that in principle is not available in the organization itself; it allows internal staff to focus mostly on current operations and to learn by doing new processes; and the transparency of cost of change is higher to the governance body and external auditors.

External consultants are very valuable in providing benchmarking and developing alternative courses of action, based on the best practices for adaptation and implementation internally. At the same time, it is important to stress that implementation follows strictly the leadership decision, with full accountability of this leadership team.

It is not by chance that we differentiate between contractors and consultants - contractors are hired to support current operations, when consultants are contracted to support change. The change team normally is a mixture of external consultants and internal staff in consultant roles. In very specific cases, we could hire contractors to 
backfill positions of internal staff, moved to work on change projects. In this case internal staff is a kind of consulting force for change (based on specific competences and skills for change, but at the same time knowing the organization from inside), when contractor is filling the empty post freed by this internal staff member in order to provide proper functioning of current operations.

Special role in the case of NCIA is the role of NATEXes (National Technical Experts) or representatives of the customers at large. In addition to adding their unique expertise and with no/little cost from the IT organization, it is important to mention that these people could improve dramatically the performance, bringing the customer and their expertise in the very early stages of project development and keeping excellent communication channel open during the whole project execution/ service provision.

\section{Internal and External Audit and Correction Planning}

In addition to the regular reviews, reporting and assessments of the governance and management bodies, it is of great importance to maintain the system of internal audit, that in confidence inform the management on the level of maturity of key processes and recommends corrective measures in consultation with the respective leaders and owners of these processes. This internal audit is a powerful instrument of change management and continuous improvement that prepares the organization for more successful performance to be measured by external auditors.

In most of the cases the internal audit cell is using consultants for the specific audit missions, that provides solid professional confidence in assessment and recommendations.

One key rule is to be able to keep the audit report management-in-confidence and to be protected from access by the customers (while, to the extent possible, it is open for the governance bodies of the IT organization). Good lesson to learn is the need for synchronization between change management priorities, risk management efforts and internal audit, because internal audit is to provide independent and professional advice for more effective change management and reducing the risks to the organization.

\section{The Way Ahead of Using NATO IT Model}

Building of mature NATO C\&I Agency was one of the most challenging tasks from Lisbon Summit - part of Agency reform. Starting from the mandate for change, through business case to select the preferred option, followed by the transition program, all the 28 nations and agency team were working hard to find the best solutions to the various problems, based on the best practices in IT Governance and Management, recognized by the NATO nations, involving many consultants, passing through several assessments / studies and audit reports (from internal audit to IBAN International Board of Auditors for NATO). This makes experience of 2010-2016 transition really unique and at the same time universal enough to be used in the practice of NATO/partner nations going in the same direction - consolidating their de- 
fence / national C\&I agencies for increased effectiveness, efficiency and tangible savings in providing $21^{\mathrm{st}}$ century IT support / services to the various customers.

This paper tries to cover the big picture with expectation several separate, but related to this picture papers to explore in more detail and professional way the approaches used in transition program to build effective NCIA and reach the maturity level 3-4 in key areas of operation.

Based on the review of NCIA experience with related good practices and mistakes to avoid in the future, we could consider that foundations are set for the general methodology of successful implementation of the projects for institution building and change management in complex IT organization in support to large public / business customer base.

Key steps to go through are:

1. Defining clear mandate for change

2. Establishing proper governance structure

3. Form strong management structure with clear leadership

4. Prepare proper change plan and operations plan, that are fully synchronized and proper funded (even through different streams)

5. Effective implementation, reporting, assessment and correction on regular basis

6. Formal transition from one to another level of maturity with normative changes

7. Timely establishment of the system of continuous improvement when performance of the organization is stabilized on the level 3 of maturity

Key aspects / processes to take care of are:

1. Planning at all level with adequate reporting, assessment, correction

2. Service delivery based on costed catalogue of services and SLAs

3. Capability development under proper program management with smooth transition to service and retirement of services / utilization of obsolete capabilities and effective acquisition support

4. Effective customer and in large stakeholder relations management

5. Personnel development, including performance management

6. Risk management

7. Science and technology / innovation management

The risks to take care of are difficult to put in general - they depend on potential weakness in governance and management, performance of the organization internally as well as some significant changes in the environment. What is important in any case - we need to review and assess risks, plan mitigation measures and maintain focus on:

1. Clear leadership - for change and current operations, but fully synchronized to provide strategic agility;

2. Rapid decision making and unity of top management along the strategy; 
3. Fluidity of resources to support implementation of what is decided with visible results to be communicated;

4. Real partnership with customers and other key stakeholders to contribute to each other success;

5. Balancing rotation of the people with continuity of business and maintaining of high motivation, including through personnel development and appreciation, use of contractors and consultants;

6. Clear accountability of industry for all external contracts and maintaining level of flexibility, required for urgent requirements;

7. Development and maintaining the culture of innovation and risk management.

There is a specific aspect to be addressed, related to science and technology, because IT organizations are strongly dependent on technological developments, research and innovation (in the case of NCIA this aspect is related to collaboration between the agency and NATO Science and Technology Organization STO).

Recognizing that C4ISR is a glue for all other elements of the system (system of systems), there is a crucial area of collaboration with agencies dealing with platforms (for NATO/defence area this includes weapon systems as well and cooperation between NCIA and NSPA /NATO Support and Procurement Agency/)

Last, but not least is collaboration in the partnership network of similar C\&I structures on national and multinational level - if the above two areas of work could be considered as vertical - this last one is horizontal among sister organizations. Such a horizontal cooperation is critical for interoperability, security and capacity management.

\section{Conclusion}

Every case of building IT organization and managing change is specific, but NATO is probably the best laboratory, "owned" by the 29 of the most advanced nations in the world to achieve excellence in C4ISR with unique contribution to interoperability and security in coalition environment. What is agreed in NATO, for sure is applicable in any NATO nation and even if the rule is to achieve "the minimum capability requirement" for common funded projects, we see that what is achieved in NATO is really high standard and definitely "good enough" for any NATO and partner nation - at least an excellent reference point for further improvements on national/ multinational level with guarantee for interoperability and security.

It means, and this is a strong belief of the author, that the above model for institution building and change management for IT organizations is a very good starting point for any effort in this area on national or multinational level. We could use such a compendium of papers, covering different areas highlighted, for facilitating "As-Is" assessment of target IT organization, supporting the process of the development of "To-Be" design and of course to plan the transition, based on lessons learnt and best practices. 
In the paper many functional areas are addressed, but they are supporting two main processes:

- Deliver a value to the customer (operations);

- Change to deliver results to the governance body (and indirectly to the customers as well).

We could add a requirement for the effective and efficient organization - developing and operating of a matrix that provides clarity on accountability and responsibility for every process of all functional areas reviewed (with clear accountability for effective operation of every functional element).

Development of IT organization for the public sector, especially the security sector is a huge task and will be solved in different ways in different nations and administrations. Developing a reference model for institution building and change management, based on agreement between 29 nations, could be an efficient tool for Chief Information Officers (Chief Digital Officers) to manage the best possible way processes in different administrations, following specific guidance from the leadership and limitations of the environment.

There are many standards and compendiums of good practices, but real experience in the development of an organization such as NCIA is a living reference model for practical implementation of the various approaches available.

Periodic assessment of the maturity and health of the reference organization could be a valuable source of proved best practices for the nations, involved in building NCIA through the Agency Supervisory Board.

Last, but not least, the nature of C\&I/IT organizations is such, that helps the experience in institution building and change management of these organizations to be used when we plan improvement in any other capability development/ service provision body.

\section{Acknowledgements}

This paper is dedicated to the people that helped me to be part of an exciting change in IT support to NATO as part of the NATO Reform. I want to specifically extend my gratitude to:

MGen. Georges D'hollander (ret.) for warm welcome and support in the NC3A (NATO Consulation Command and Control Agency) to the development of C4ISR comprehensive approach, establishment of bilateral Memorandums of Understanding (MoUs) with several nations and introduction of the first NC3A Catalogue;

Mr. Kevin Scheid for exemplary leadership as the $\mathrm{COO}$ and support in establishment of multi-year program of work (MYPOW) with the nations, development of innovative approaches as $\mathrm{C} 4$ Trust (Integration) Fund model; 
Mr. Paul Ballinger for the introduction to the customer funding and resource management in the complex environment of NATO, supporting the efforts to serve variety of customers;

MGen. Koen Gijsbers (ret.) for change management leadership, involving me in the most exciting transformation project to merge 5 diverse NATO agencies in one great service based, customer funded organization, and embracing support to nations and force structure with the CIO conference;

Mr. Dag Wilhelmsen and Klaus Niemeyer for long term cooperation that attracted me in the NC3A; leadership and deep technical expertise of Dag as the Transition Director that helped me to position the Demand Management as a driver for change;

Mr. Chuck Shawcross for introducing professional approach to change in building service based organization and bringing innovation in the center of our activities;

Mrs. Anne-Marie Pick for driving the development of unified approach to customers in customer funding environment and bringing us together for integrated customer support;

BGEN Luigi Tomaiuolo for excellent partnership with CIS support units and intro $\neg$ ducing change in support to operations and exercises;

Dr. Gregory Edwards for creating the Connected Forces Readiness program and moving it further to NATO Readiness and Interoperability program, that helped us to meet the challenge of Readiness Action Plan (RAP) and go further with forward presence initiatives;

Mr. Enzo Montalti for helping me to understand the most complex program for air command and control and especially the most important part of it - relations between the people;

RADM Thomas Daum for the confidence to work together on the very critical aspects of transition related to resource management, planning, measurement, and reporting;

Mr. Peter Scarupe for the real partnership in acquisition support to urgent customer requests and development of new models to support nations and force structure when it comes to acquisitions for exercises and operations;

Mr. Murray Davidson for his energy and professional approach to move our change efforts to the next level with focus on customer accounts;

Mr. Paul Smith for excellent cooperation in strategic planning, development of new concepts, and engagement with the stakeholders to provide support to these initiatives;

Mr. Wolfgang Taubert and MGen (ret.) Peter Treche - for building true partnership with AFCEA Int., bringing ideas and drive for change in NCIA; 
Mr. Christophe Picot for support to build demand management team from scratch in very difficult environment (ret.) without the help of HR to recruit, move, develop, motivate the people it would not have been possible to reach level three-four of organization maturity;

Mrs. Simona Rocchi for excellent cooperation in the development of the legal base for partnerships with the customers, introducing multinational projects, C\&I partnerships, SLAs, C4 Trust Fund and all other instruments to bring NATO solutions to nations;

Mr. Mario Quarta for supporting us through internal audit missions to move to higher levels of maturity in critical areas and in close cooperation with all the elements of the Agency;

Demand management (DM) team and especially Nadja, Xavier, Agata, Eric, Tim, Els, Adrian, Eloise ... all colleagues, civilian and military (especially our executive officers Dirk, Frank, Amleto, Stefan) that motivated me to work hard for achieving our goals, to build true partnership with customers and inside the agency for NATO success (in early stages I am very grateful to all people supporting DM on project base with special gratitude to Sherri Acker and Mike Rudack).

I will certainly not forget Mr. Tim Harp and Ms. Barbara Gregory from the NCIO Agency Supervisory Board, many colleagues from NHQ C3 Staff and definitely leadership of our customers - especially members of Senior Customer Supplier Board (SCSB) and leasders from command and force structures - LTGen Ben Hodges, VADM Johnstone, and LTGen Hofmann, for the unique opportunity for the breakthrough in the area of the NCIA support to the force structure.

Commitment of the CIO of the Pentagon Mr. Halvorsen and the CIO of UK MoD Mr. Stone to the annual CIO conference of NATO nations made a real difference in positioning the NCIA as the IT agency of NATO and nations.

Last, but not least I want to express my appreciation to my mentor Mr. Loren Diedrichsen - first GM of the NC3A, who since 1992 is helping me to keep focus on C4ISR and to stay engaged in that area despite many different assignments the life brought me in. And I hope I will be engaged with NCIA in the future as well. MGen Emmanuel Greindl sadly is no longer with us, but he was the one opening the AFCEA-Europe doors for C4ISR community in Eastern Europe to cooperate with our western colleagues, and guided me on the way to the NC3A.

Definitely it is not possible to mention all colleagues we worked together these 7.5 years to create the best international IT agency in the world, but important is to recognize the effort of all people involved, from whom I learned a lot.

What is even more important - to work together and to have sister agencies in all member and partner nations, engaged with the NCIA create C4ISR partnership network for best possible IT support to the best defense alliance in the world - NATO. 


\section{References}

1 NATO C4ISR Comprehensive Approach (Brussels, NATO C3 Board and NC3A, 11 November 2009).

2 COBIT 5: A Business Framework for the Governance and Management of Enterprise IT, available at www.isaca.org/cobit (29 June 2017).

3 James R. Persse, Process Improvement Essentials: CMMI, Six Sigma, and ISO 9001, First Edition (Sebastopol, CA: O’Reilly Media, 2006).

4 Yves L. Doz and Mikko Kosonen, Fast Strategy: How Strategic Agility Will Help You Stay Ahead of the Game (Harlow, England: Wharton School Publishing, 2008).

5 Jim Collins and Morten T. Hansen, Great by Choice: Uncertainty, Chaos, and Luck - Why Some Thrive Despite Them All (New York, NY: HarperCollins, 2011).

6 Robert Kaplan and David Norton, The Balanced Scorecard: Translating Strategy into Action (Harvard, MA: Harvard Business School Press, 1996).

7 Robert Kaplan and David Norton, Alignment: Using the Balanced Scorecard to Create Corporate Synergies (Harvard, MA: Harvard Business School Press, 2006).

8 Jeffrey M. Hiatt; ADKAR: A Model for Change in Business, Government and our Community (Loveland, CO: Prosci Inc., 2006).

9 John Carroll, Project Program and Portfolio Management in Easy Steps (Warwickshire, UK: Easy Steps Limited, 2014).

10 Ernest Brewster, Richard Griffiths, Aidan Lawes, and John Sansbury, IT Service Management: A Guide for ITIL Foundation Exam Candidates, Second edition (Swindon, UK: British Informatics Society Limited, 2012).

\section{About the author}

Dr. Velizar Shalamanov has a master's degree in radioelectronics from the Air Force Academy in Dolna Mitropolia, a master's degree in management and organization of operational and tactical intelligence from the Defence and Staff College in Sofia and a doctoral degree in cybernetics from the Kiev Air Defence Radio Technical Academy. He graduated several specialization courses in USA and Germany, including senior executive seminar in Marshall Center, Garmisch-Partnekirchen. In 1998 he became associated professor. Between 1998 and 2001 he was a deputy defence minister for defence policy, planning and integration. In 2001-2009 he worked as an advisor to the chairperson of the Bulgarian Academy of Sciences on national security and defence and led IT Systems R\&D section in the institute of parallel processing. Shalamanov also taught in various Bulgarian universities. He has been leading various NGO's and was a member of Geneva Centre for DCAF International Advisory Board (2002-2012), ESRIF (2007-2009). Currently, he is member of AFCEA Int. Executive Committee and BoDs. In the period 2009-2017 Dr. Shalamanov was director sponsor account NATO \& Nations in NC3A (2009-2012) and director demand management in NCIA (2012-2017). In the period August-November 2014 he was called to serve as a Minister of Defence in Bulgaria's Caretaker government appointed by President Plevneliev. Currently, Dr. Shalamanov is Associated Professor in the Institute of Information and Communication Technologies, Bulgarian Academy of Sciences. E-mail: shalamanov@acad.bg. 